\title{
The effect of meaning on the allocation of visually induced movement
}

\author{
LEONARD BROSGOLE AND PATRICIA M. WHALEN
}

NAVAL TRAINING DEVICE CENTER

The directional characteristics of a meaningful target were found to affect its apparent motion when it was displaced relative to a neutral object. The effect was destroyed, however, when the target was surrounded by a frame. This was because the frame imparted a meaning which tended to override that conveyed by the target.

There are properties attributed to stimuli, on the basis of prior experience, which may concelvably affect the allocation of visually perceived movement. Of the countless number of objects functionally capable of moving, some have been associated with a specific direction of motion exclusively. For example, airplanes fly forward and not backwards and bombs tend to fall, not to rise. The question has been raised as to whether this level of meaning will affect the direction in which such figures can be induced to move, since induced motion is a phenomenon which is allegedly determined by factors outside of past experience.

Regarding this issue, Jensen (1960) presented a stationary silhouette figure of an airplane, facing to the right, along with a laterally displacing vertical bar. He found that it was significantly easier to induce the plane to move forward than backward. Unfortunately, he did not quantify the precise amount of induced motion perceived, nor did he use such appropriate controls as pointing the stimulus to the left or, at least, presenting a neutral target in a separate condition. The way Jensen's data stand, it is impossible to determine whether his Ss preferred a forward movement or an apparent motion to the right. The first experiment, therefore, was aimed at replicating Jensen's findings with a more sophisticated design.

\section{EXPERIMENT 1}

In order to ascertain to what extent visually perceived movement is affected by the directional characteristics of a stimulus, a three dimensional model of an airplane was displaced relative to a vertical line. The target faced to the right in one instance and to the left in another. The plane was replaced by a neutral target in a third condition. The amount of motion induced in each of the targets was obtained with exact precision.

\section{Apparatus}

The equipment has been described in greater detail elsewhere (Brosgole, 1967). It basically consisted of a wooden screen (60 in. high $\times 30$ in. wide) upon which stimuli could be mounted. It was driven back and forth along a set of tracks by a motor via a network of gears and pulleys. It traveled $22 \mathrm{in}$, across space at a rate of $20^{\prime}$ of visual arc:er sec. At the end of its journey, the screen activated a relay which reversed its direction of travel. The apparatus was remotely operated by $\mathrm{E}$.

Provision was made for housing a stimulus directly in front of the screen. The $S$ was able to remotely control the spatial location of the target by turning a circular control knob fixed to the shaft of a Selsyns synchronous motor. He was able to move the target 60 in. across space, $30 \mathrm{in}$, to the right and left of the objective median plane. The position of the screen and target was automatically plotted on a Brush strip chart recorder.

\section{Stimuli.}

The target consisted of a model of a British fighter plane which was luminously painted. It was 9 in. long and was rolled over to one side so that its wing tips were separated vertically by 2 in. A marking was placed midway along the fuselage to facilitate instructions. A luminously painted solid rectangle was used as a neutral target. It was 9 in. long $\times 2$ in. high. An 18 in. $x 1$ in. luminous vertical line was mounted on the screen so as to constitute the inducing stimulus.

\section{Procedure}

The experiment took place in total darkness with $S$ positioned in a head and chin rest $10 \mathrm{ft}$. from the apparatus. He participated in three conditions. In the first, $S$ viewed the plane which was facing to the right, located directly in front of the vertical line. Both the line and the marking on the fuselage were placed in the objective median plane. The $\mathrm{S}$ was told to adjust the plane with the control knob so that the marking appeared directly straight ahead, i.e., perpendicular to the midline of his body. He was then informed that $\mathrm{E}$ could arbitrarily move the line, the plane, or both in the same or opposite directions at any given time. He was instructed to fixate the plane and to keep it straight ahead, ignoring the line at all times. Only the line was set in motion. In half of the cases it displaced from center to the right by 11 in., back through the center to the left by 11 in., and back to center again for three such cycles or trials. In the other half, its initial motion 
was to the left. The S's continuous adjustments served to indicate the amount of motion induced in the target. The line induced a forward motion in the target as it shifted to the left and a backward motion as it displaced to the right.

The second condition was identical to the first except that the plane pointed to the left. The plane was replaced by the rectangle in the third condition with everything else held constant. The order of the three conditions was counterbalanced over Ss.

\section{Subjects}

Nine males and six females participated in this study. Ranging in age from 17-23, their mean age was 19.4 years. They were undergraduate students from $C$. W. Post College. All were naive as to the purpose of this study.

\section{Resulits and Discussion}

We will first consider how the vertical line influenced each of the targets as it displaced to the right. In Condition 3, the neutral stimulus was induced to move on an average of $3.57 \mathrm{in.} \mathrm{to} \mathrm{the} \mathrm{left.} \mathrm{The} \mathrm{plane}$ appeared to move $6.56 \mathrm{in}$. to the left, or forward, in Condition 2 and 2.37 in. to the left, or backwards, in Condition 1. These differences were significant according to the Friedman Two Way Analysis of Varlance $\left(x_{r} 2=9.04, d f=2, p<.02\right)$. The Binomial Test indicated that the induced forward motion of the plane was significantly greater than its apparent backward movement $(p<.01)$. It was also reliably more than the leftward motion exhibited by the control stimulus $(p<.02)$. The amount of apparent leftward motion in the neutral target, however, did not statistically exceed the backward movement of the plane.

Essentially the same results were obtained when the line displaced to the left. It induced the neutral target to move 0.66 in. to the right. In Condition 1 , the plane appeared to shift to the right, or forward, by 4.61 in. It was also seen to go slightly forward in the second condition, as it seemed to move 0.27 in. to the left. The Friedman Analysis of Variance indicated that these differences were significant at the $1 \%$ confidence level $\left(x_{r^{2}}=11.79, d f=2\right)$. According to the Binomial Test, Condition 1 yielded significantly more motion than Conditions $2(p<.02)$ and $3(p<.01)$. The latter two treatments did not reliably differ.

We may conclude, on the basis of the above evidence, that significantly more motion is attributed to a fixated target when it is induced to move in a forward direction. However, it is just as frequently seen to move backwards although not to so great an extent. Under such circumstances, the target seems to be treated as if it were a neutral stimulus.

\section{EXPERIMENT 2}

The first study indicated that prior experience seems to affect the manner in which visually perceived movement is distributed between two objects in the field. We now sought to inquire whether meaning would tend to display the same effect when the total amount of movement is to be divided between a target and a surround.

\section{Apparatus}

The displacing vertical line, used in Experiment 1 , was replaced by a luminous frame. The frame was 30 in. wide $\times 24$ in. high. It was oriented horizontally with its vertical center at eye level. With this one exception, the general method and procedure remained unchanged.

\section{Subjects}

Seven males and eight females served as Ss. Ranging in age from 18 to 24 , their mean age was 21.6 years. They were undergraduates from $\mathrm{C}$. W. Post College and were naive as to the purpose of this study.

\section{Results and Discussion}

As the frame displaced to the right, the neutral target was induced to move an average of $10.88 \mathrm{in}$. to the left. The plane appeared to move $9.97 \mathrm{in}$. forward and to the left and 9.0 in. to the left in a backward direction. These differences were not significant according to the Friedman Analysis of Variance $\left(X_{r^{2}}=0.429\right)$.

Similarly, as the frame shifted to the left, the control stimulus was induced to move $8.09 \mathrm{in}$. to the right compared to a $6.62 \mathrm{in}$. forward motion of the plane and a 7.33 backward movement. These differences were also not significant $\left(X_{r} 2=1.750\right)$.

Surrounding a target with a frame, then, destroys whatever effect stimulus meaning seems to have on the allocation of visually perceived movement. The reasons for this will be explored in the following study.

\section{EXPERIMENT 3}

Experiment 2 gave rise to the question of whether a surrounding frame carries a meaning of its own which tends to override that conveyed by the enclosed stimulus. One possible hypothesis is that the frame had canceled out the target's effect by virtue of its size. That is to say, there is a tendency to ascribe a certain amount of motion to the smaller of two objects, on the basis of past experience, regardless of its directional characteristics. Another possible explanation is that the frame served as an enclosing surround and, since backgrounds usually remain perfectly stationary, the direction in which a target is facing should have no bearing on the extent to which it can be induced to move.

The following experiment, therefore, was directed at evaluating the effect of enclosure while holding field size constant. 


\section{Apparatus}

The same equipment was again employed.

\section{Stimuli.}

The previously used frame was now presented in conjunction with a 1 in. diameter luminous sphere. The sphere was the only target utilized.

\section{Procedure}

This study consisted of three conditions. In the first, the frame was presented with its lower border 1 in. above the target. It surrounded the target in the second condition and, in the third, its upper horizontal border appeared 1 in. below the target. The target was always presented at eye level. The only enclosing condition, then, was the second. The balance of the procedure remained unchanged, i.e., $S$ continuously adjusted the target to the phenomenally straight ahead location, etc.

\section{Subjects}

Six males and six females participated in this study. Ranging in age from 17 to 21 , their mean age was 18.9 years. They were again undergraduates from C. W. Post College who were naive as to the intent of this experiment.

\section{Resulis and Discussion}

The location of the target was noted when the frame was at its extreme left and right positions. The difference between these settings of the target represented the range of induced motion generated by the frame. A mean range was calculated for each $\mathrm{S}$.

If the effect of a frame is contingent solely upon its size, then the three treatments should have yielded no differential data. However, if it is based strictly upon the factor of enclosure, then the second condition should have generated significantly more motion than the others. Unfortunately, our results did not tend to support either of the two aforementioned hypotheses.
Averaging across Ss, a mean range of 7.44 in. was found in the first condition compared to 10.75 in the second and 9.23 in the third. These differences were significant according to the Friedman Analysis of Variance $\left(X_{r}=7.04, d f=2, p<.05\right)$. The Binomial Test indicated that while Conditions 2 and 3 were essentially the same, they both differed significantly from Condition 1 ( $p<.02$ in each instance).

The question arises as to whether Treatments 2 and 3 may have shared anything in common which caused them to differ from Condition 1 . It became obvious, after a bit of pondering, that they both provided stimulation beneath the target. We believe that this may have served as a floor or terrain against which the target could displace and, furthermore, that this is precisely the meaning conveyed by an encapsulating background. There are several informal observations which tend to support this point of view.

For example, when the background was held constant and the target was displaced back and forth directly underneath it, the relatively huge frame was induced to move. Horizontally displacing the target immediately above the frame, on the other hand, produced no effect. In addition, when the displacing target was positioned within the frame, adjacent to its lower border, the surround was induced to move rather noticeably - a phenomenon never before demonstrated. Unfortunately, the nature of our equipment did not permit us to pursue these matters any further. We are convinced, however, that a background is most effective when it provides a ground plane.

\section{References}

Brosgole, L. Induced autokinesis. Percept. \& Psychophys., 1967, 2, 69-73.

Jensen, G. D. Effect of past experience upon induced movement. Percept. mot. Skills. 1960, 11, 281-288.

(Accepted for publication March 10, 1967.) 